WHITE PAPER

\title{
System Engineering Program Applicability for the High Temperature Gas-Cooled Reactor (HTGR) Component Test Capability (CTC)
}

Jeffrey D. Bryan

June 2009

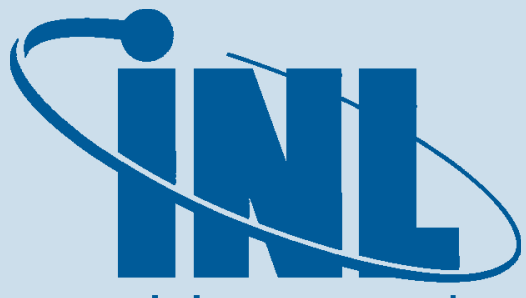

Idaho National Laboratory

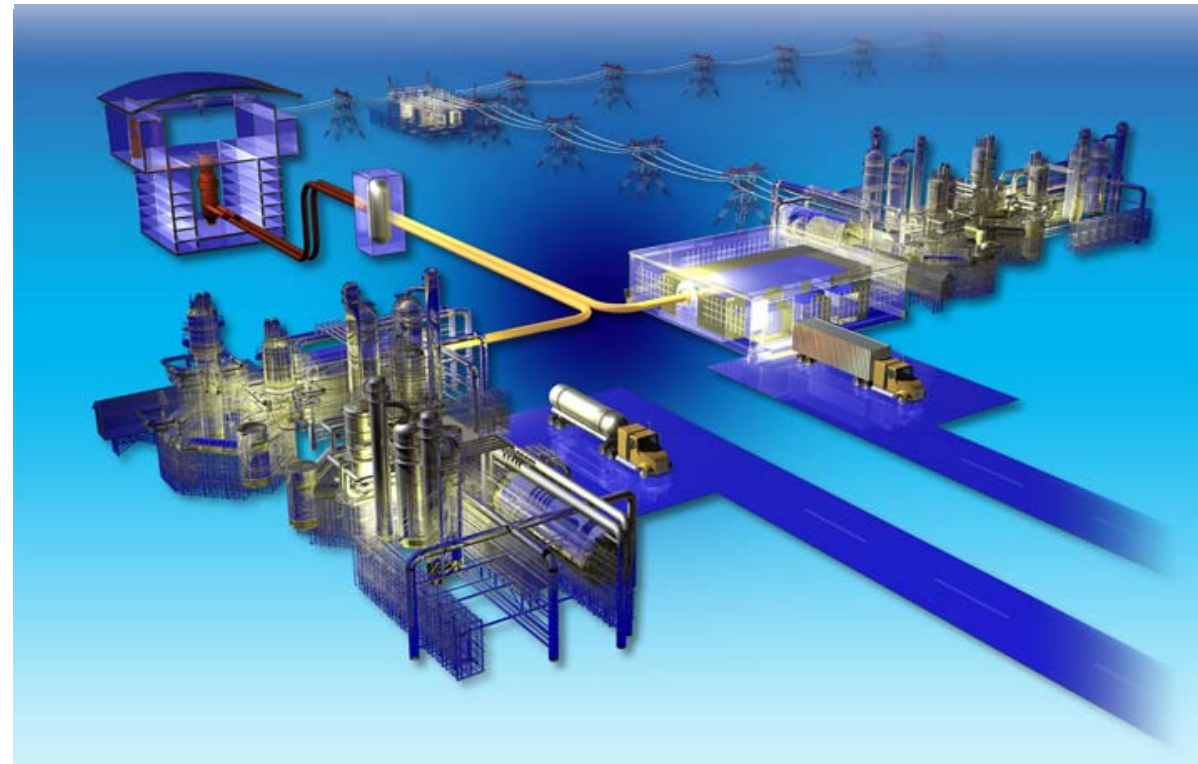

The INL is a U.S. Department of Energy National Laboratory operated by Battelle Energy Alliance. 


\section{DISCLAIMER}

This information was prepared as an account of work sponsored by an agency of the U.S. Government. Neither the U.S. Government nor any agency thereof, nor any of their employees, makes any warranty, expressed or implied, or assumes any legal liability or responsibility for the accuracy, completeness, or usefulness, of any information, apparatus, product, or process disclosed, or represents that its use would not infringe privately owned rights. References herein to any specific commercial product, process, or service by trade name, trade mark, manufacturer, or otherwise, does not necessarily constitute or imply its endorsement, recommendation, or favoring by the U.S. Government or any agency thereof. The views and opinions of authors expressed herein do not necessarily state or reflect those of the U.S. Government or any agency thereof. 
WHITE PAPER

\title{
System Engineering Program Applicability for the High Temperature Gas-Cooled Reactor (HTGR) Component Test Capability (CTC)
}

\author{
Jeffrey D. Bryan
}

June 2009

\begin{abstract}
Idaho National Laboratory
Next Generation Nuclear Plant (NGNP) Project

Idaho Falls, Idaho 83415
\end{abstract}

Prepared for the

U.S. Department of Energy

Office of Nuclear Energy

Under DOE Idaho Operations Office

Contract DE-AC07-05ID14517 

Next Generation Nuclear Plant (NGNP) Project

WHITE PAPER

System Engineering Program Applicability for the High Temperature Gas-Cooled Reactor (HTGR) Component Test Capability (CTC)

INL/EXT-09-16315

June 2009

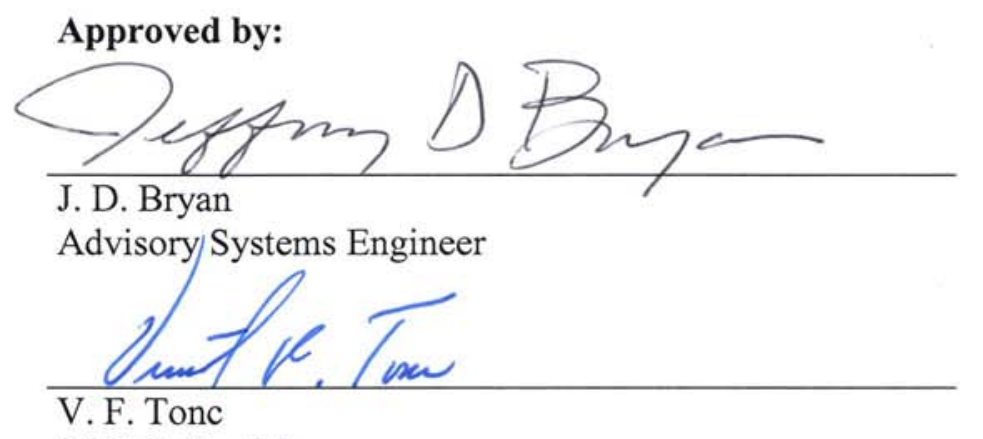

CTC Project Manager

Vondul Saws

NGNP Project Engineer

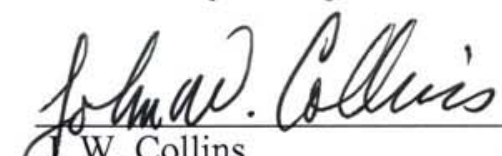
NG. Collins

NGNP Lead Systems Engineer
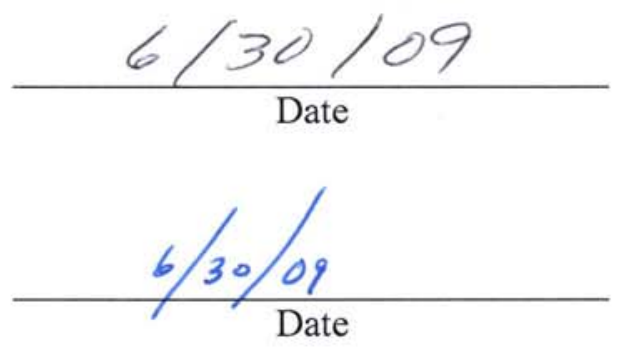

4/30/09

Date

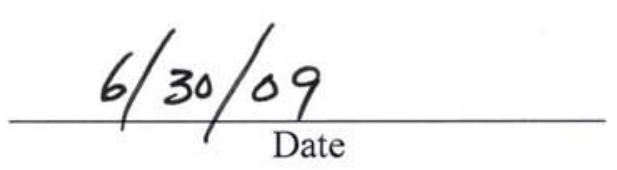





\section{CONTENTS}

ACRONYMS viii

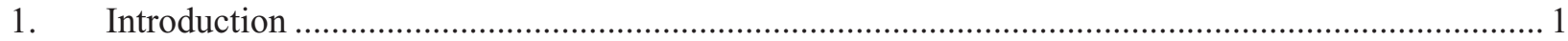

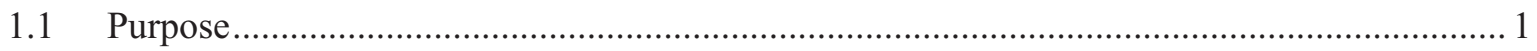

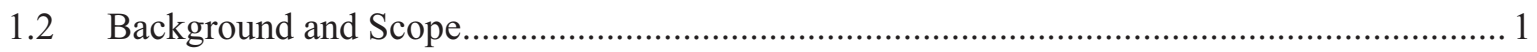

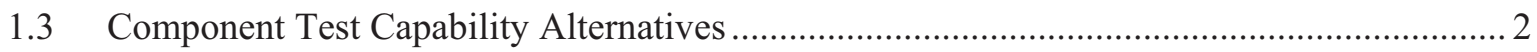

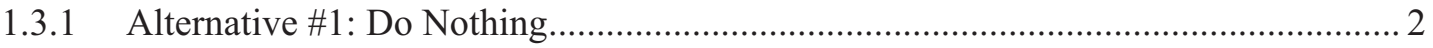

1.3.2 Alternative \#2: Vendor Distributed Testing ........................................................... 2

1.3.3 Alternative \#3: Modification of Existing Testing Facilities........................................ 2

1.3.4 Alternative \#4: Single, Standalone Component Test Facility .................................... 3

2. Systems Engineering and Technical Management Considerations ............................................. 3

3. Alternative Systems Engineering and Technical Management Application ................................... 3

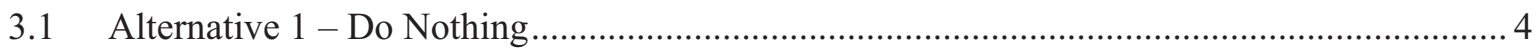

3.2 Alternative 2 - Vendor Distributed Testing .................................................................. 5

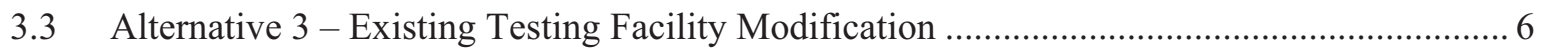

3.4 Alternative 4 - Component Test Facility ........................................................................ 7

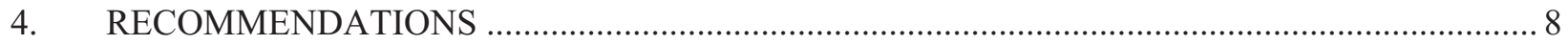

\section{FIGURES}

Figure 1. SEMP Applicability for the CTC Alternatives ...............................................................

Figure 2. SEMP Applicability for Alternative \#4, Component Test Facility .......................................... 7 


\section{ACRONYMS}

BEA Battelle Energy Alliance, LLC

CD critical decision

CTC Component Test Capability

CTF Component Test Facility

DOE Department of Energy

DOE-ID Department of Energy, Idaho Operations Office

HTGR High Temperature Gas-cooled Reactor

INL Idaho National Laboratory

LWP Laboratory-wide Procedure

NGNP Next Generation Nuclear Plant

NSUF National Scientific User Facility

OKMB Afrikantov Experimental Machine Building Design Bureau

PBMR Pebble Bed Modular Reactor

PEP Project Execution Plan

PLN Plan

SEMP System Engineering Management Plan

SSCs structures, systems, and components 


\title{
System Engineering Program Applicability for the High Temperature Gas-Cooled Reactor (HTGR) Component Test Capability (CTC)
}

\author{
1. Introduction
}

\subsection{Purpose}

This white paper identifies where the technical management and systems engineering processes and activities to be used in establishing the High Temperature Gas-cooled Reactor (HTGR) Component Test Capability (CTC) should be addressed and presents specific considerations for these activities under each CTC alternative. In particular, DOE O 413.3A, "Program and Project Management for the Acquisition of Capital Assets," and DOE G 413.3-1, "Managing Design and Construction Using Systems Engineering for Use with DOE O 413.3A," will apply in the event that Alternative \#4, a standalone component test facility, is selected and approved. As such, it is advisable to begin planning to meet the associated DOE requirements and guidance as early in the acquisition process as practicable. This white paper is intended to assist in this planning and to support associated decision-making activities.

\subsection{Background and Scope}

The Next Generation Nuclear Plant (NGNP) Program is conducting a trade study to select a preferred approach for establishing a capability whereby NGNP technology development testing - from material tests up through large-scale, integrated tests - can be performed for critical HTGR structures, systems, and components (SSCs). The mission of this capability includes enabling the validation of interfaces, interactions, and performance for critical systems and components prior to installation in the NGNP prototype.

Four alternatives are being evaluated in the NGNP trade study. Each of the alternatives is linked to a distinct approach for addressing NGNP technical risk. The alternatives for completing the large-scale integrated testing necessary to validate the interfaces and performance of critical systems and components prior to installation in the NGNP prototype include:

1. Do nothing - no large-scale testing of NGNP critical SSCs

2. Distribute the testing requirements to the component and system vendors as part of the specifications for procurement

3. Modify existing facilities (mostly overseas) to support NGNP large-scale testing needs

4. Construct a stand-alone facility to house and operate test loops designed to meet NGNP largescale testing needs.

These alternatives are summarized in Section 1.3, with applicable technical management and systems engineering considerations described in Section 3. 


\subsection{Component Test Capability Alternatives}

The following subsections describe the alternatives under consideration for providing the HTGR CTC.

\subsubsection{Alternative \#1: Do Nothing}

This alternative reflects the NGNP Program adopting a risk acceptance response strategy for the technology risks associated with the critical HTGR SSCs. Under this alternative, no technology development or large-scale testing of critical SSCs will be performed except for integration testing conducted during cold start-up activities for the NGNP prototype. The NGNP design team will be responsible for all SSC engineering and for producing all designs and specifications for the prototype's SSCs.

Prescriptive specifications will be issued by the NGNP Program to vendors who build the SSCs per those specifications. The completed SSCs will then be shipped to the NGNP prototype where they will be evaluated for acceptance and installed in the prototype reactor. The NGNP Program will retain liability for the SSCs' reliability, operability, etc., and any defects will have to be addressed and repaired (or replaced) during startup or hot operations.

\subsubsection{Alternative \#2: Vendor Distributed Testing}

This alternative reflects the NGNP Program adopting a "risk transfer" response strategy to reduce the technology risks associated with critical HTGR SSCs. Under this alternative, risk and technology development associated with critical SSCs materials of construction, performance, safety, and operation will be transferred to the vendor through the use of performance specifications. It will be left to the vendors to decide the amount, types, and levels of material and technology development testing that they will perform to meet the NGNP performance specifications. Vendors will fund any modification or construction of test capabilities that they need to manage their liabilities and support their development and testing plans relative to their SSCs. It is expected that the vendors will amortize any test capability implementation costs they incur as part of their SSC bid price. Then, as in Alternative \#1, the NGNP Program will perform integrated testing of the critical SSCs as part of cold start-up and hot operation activities for the NGNP prototype.

\subsubsection{Alternative \#3: Modification of Existing Testing Facilities}

This alternative reflects the NGNP Program adopting a "risk reduction" response strategy to address the technology risks associated with critical HTGR SSCs. Under this alternative, one or more existing facilities will be utilized to the fullest extent possible to support material and technology development, large-scale, and, possibly, integration testing for critical HTGR SSCs. Technologies to be tested could be those proposed by vendors or those developed by vendors to meet NGNP designs and specifications. Existing facilities under consideration include:

1. Pebble Bed Modular Reactor (PBMR) facilities in the Republic of South Africa, where test loops could be designed and installed at either the High Temperature Helium Test Facility or in a new facility.

2. Afrikantov Experimental Machine Building Design Bureau (OKBM) facilities in Russia, where test loops could be designed and installed at the Russian Large Scale High Temperature Helium Test Facility. These facilities were built in the 1970s and operated to the 1980s. They have been deactivated and in a prolonged storage state since that time. 
This alternative can be implemented in several different ways relying on vastly different contracting strategies. Two of the options under investigation are:

- Procure testing "services" from the "user" facility. This case has already been tested with NGNP R\&D testing performed at university facilities.

- DOE becoming a "partner" or "leaser" in an upgraded "user" facility while retaining some ownership in the capital investment.

\subsubsection{Alternative \#4: Single, Standalone Component Test Facility}

This alternative also reflects the NGNP Program adopting a "risk reduction" response strategy to address the technology risks associated with critical HTGR SSCs without introducing the residual risks associated with Alternative \#3. In this alternative, a single, standalone facility will be constructed to house and operate test loops designed to meet NGNP material and technology development and largescale testing needs for the HTGR prototype. The test facility, including any supporting utilities, will be constructed in the United States, where it will be fully-funded, owned, and operated by DOE or its representatives. After startup, the CTF could be used to test both NGNP-designed as well as vendorproposed SSCs. As an added advantage, the CTF will be available for use as a National Scientific User Facility (NSUF) following the accomplishment of NGNP SSC testing scope for ongoing HTGR component development testing and qualification and other high-temperature R\&D.

\section{Systems Engineering and Technical Management Considerations}

Technical management and systems engineering processes, activities, and tools used in defining, designing, and delivering a complex system are typically documented in the project's Project Execution Plan (PEP) or System Engineering Management Plan (SEMP). If written, the SEMP is an extension of the PEP and becomes the primary, top-level technical management plan for the planning, management, and integration of all technical and engineering activities to be performed. As such, the SEMP describes the process for planning and control of these activities for the system's design, development, testing and verification, and, finally, system validation. In addition, the SEMP documents the tailoring of the standard systems engineering approach and process activities, as appropriate, based on project attributes such as size, complexity, and technical risk.

It is with this latter attribute, technical risk, that special consideration must be given when deciding where best to manage systems engineering and technical activities pursuant to implementing the HTGR CTC. As described above, the four CTC alternatives are, in essence, varying approaches for addressing NGNP technical risk and afford differing levels of risk abatement for NGNP. Therefore, the systems engineering and technical management processes and activities to be planned and conducted under each of the CTC alternatives should be tailored appropriately to best manage the amount and type of residual technical risk those approaches continue to impart to the NGNP Program.

\section{Alternative Systems Engineering and Technical Management Application}

Battelle Energy Alliance (BEA) is under contract to DOE Idaho Operations Office (DOE-ID) for management and operations of the Idaho National Laboratory (INL). ${ }^{a}$ This contract requires BEA to

\footnotetext{
${ }^{a}$ Contract number DE-AC07-05ID14517.
} 
comply with DOE O 413.3A, "Program and Project Management for the Acquisition of Capital Assets" as well as other DOE directives, regulations, and laws. Because CTC Alternative \#4, the CTF, creates a capital asset owned by DOE, this order applies and requires the use of a systems engineering approach in planning, implementing, and completing such projects. ${ }^{b}$ On the other hand, if an alternative other than the CTF is selected, the use of a systems engineering approach (and SEMP for that matter) is not a requirement but rather becomes a best management practice in accordance with GDE-70. ${ }^{\circ}$

Figure 1 illustrates how the CTC implementation effort should be covered by the various SEMP documents (or PEP, as the case might be) depending on the alternative selected by the CTC trade study.

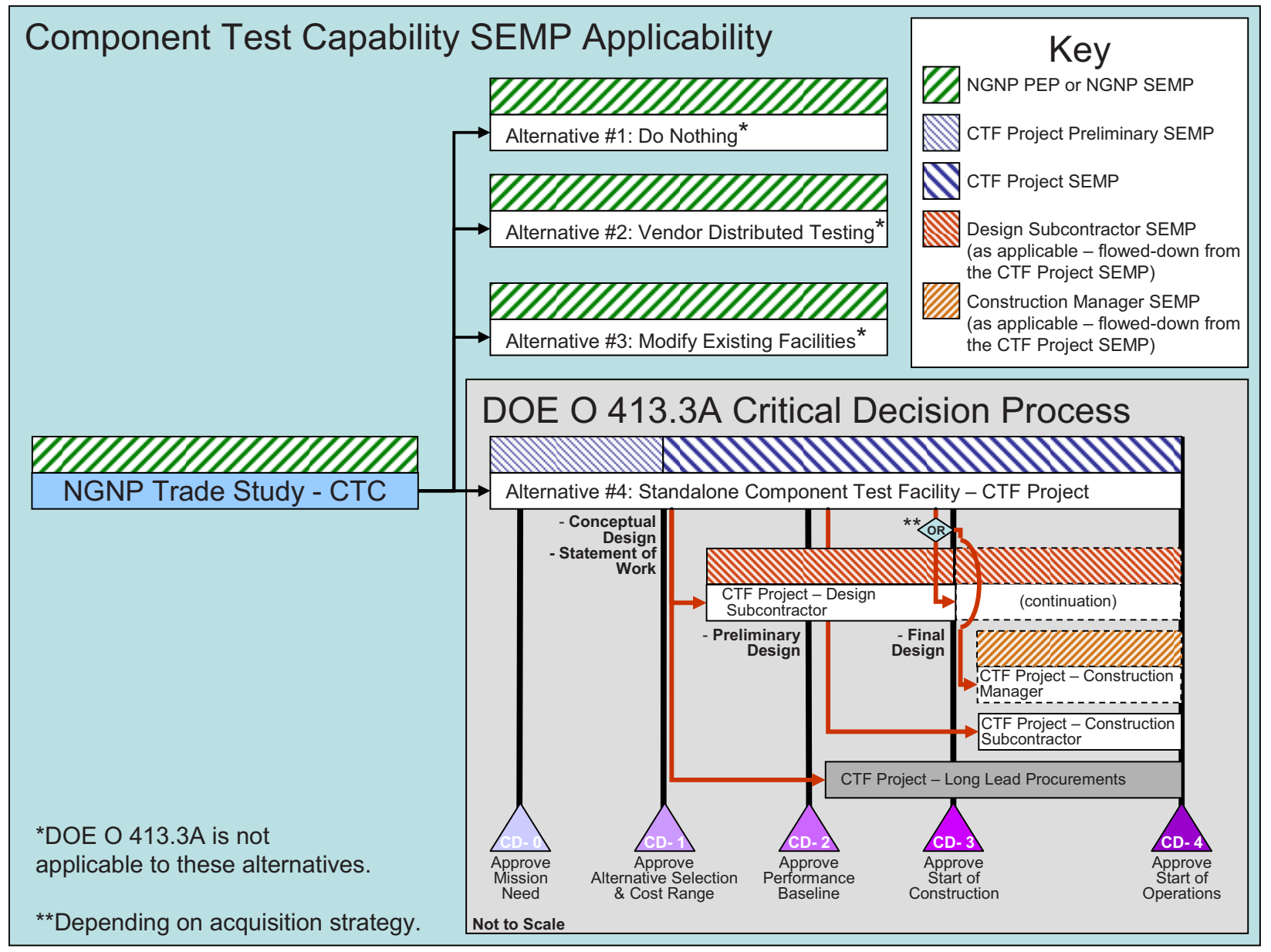

Figure 1. SEMP Applicability for the CTC Alternatives

\subsection{Alternative 1 - Do Nothing}

Alternative \#1 involves no large-scale testing of NGNP critical SSCs except during cold start-up in the plant. Thus, no capability is created under this alternative for mitigating the associated technical risks, and DOE O 413.3A does not apply. Upon acceptance of the SSCs from their respective vendors, NGNP

${ }^{\mathrm{b}}$ DOE O 413.3A Change 1, Paragraph 6g(2), dated November 17, 2008.

${ }^{c}$ GDE-70-B, Technical Strategy, Paragraph B.2., Revision 3, dated August 16, 2006. 
must accept all risk associated with SSC performance, safety, operation, materials of construction, etc., and any resulting rework or schedule delays.

As a result, a primary means for mitigating the NGNP technical risk associated with these SSCs will be through careful application and execution of systems engineering and engineering design processes to achieve the best results possible when designing and specifying the critical SSCs. In addition, a robust and well executed Risk Management Plan will also be key in controlling the technical risks.

Inasmuch as well understood or previously tested materials, designs, or off-the-shelf components may be used in these SSCs to reduce technical risk, special attention will need to be paid in the following areas:

1. Interface management and control

2. Design analyses, verification, and revision control

3. Planning for integration and verification testing

4. Issue, decision, and action documentation, tracking, and results communication.

The technical work scope-including systems engineering, design verification and control, and integration and verification testing - should be performed in accordance with the NGNP PEP or NGNP SEMP, as applicable. The design drawings and specifications should be prepared in accordance with the INL Design Control process (LWP-10400) and the NGNP Quality Program Plan (PLN-2021).

\subsection{Alternative 2 - Vendor Distributed Testing}

Alternative \#2 distributes the testing requirements to the component and system vendors as part of the specifications for procurement. Vendors perform material and technology development testing as they deem necessary to meet performance specifications. As in Alternative \#1, no integration testing of NGNP critical SSCs occurs until cold start-up in the plant. Because the vendors fund any modification or construction of testing capabilities needed to support the development and testing of their SSCs, no DOEowned capability is created under this alternative, and DOE O 413.3A does not apply.

Residual risks that must be accepted by the NGNP Program under this alternative include (but are not limited to):

1. Risk associated with errors or omissions in SSC performance specifications

2. Risk associated with unanticipated transients or adverse interactions between SSCs

3. Risk associated with latent quality issues not detected until after the "burn-in" or operational period identified in the performance specification

4. Risk associated with selection of vendors who ultimately are not capable of providing SSCs meeting the performance specification - either in terms of SSC delivery (NGNP schedule impact), cost, or technical performance.

A primary means for mitigating these NGNP technical risks will be through careful application and execution of systems engineering and engineering design processes to ensure specifications are accurate, complete, and reflect appropriate integration attributes. In addition, a robust and well executed Risk Management Plan will also be key in controlling the technical risks. Special attention will need to be paid in the following areas:

1. Vendor qualification and selection 
2. SSC specification development, review, management, and change control

3. SSC interface identification, definition, management, and change control

4. Receipt inspections and vendor data package reviews for SSC acceptance

5. Planning for SSC integration and verification testing.

Under this alternative, the NGNP Program's technical effort-including systems engineering and other activities noted above - should be performed in accordance with the NGNP PEP or NGNP SEMP, as applicable. The design drawings and specifications should be prepared in accordance with the INL Design Control process (LWP-10400) and the NGNP Quality Program Plan (PLN-2021) since the procurement or performance specifications are part of the overall NGNP plant design and scope.

\subsection{Alternative 3 - Existing Testing Facility Modification}

In Alternative \#3, one or more existing facilities will be modified to support material and technology development, large-scale, and, possibly, integration testing of NGNP critical HTGR SSCs. As such, it reduces NGNP technical risk by eliminating or decreasing uncertainties associated with design scale-up, component interface affects that can cause adverse transients or interactions, unit control schemes, and operational performance parameters (i.e., operability, reliability/dependability, availability, maintainability/serviceability/reparability, durability, and sustainability). Due to the limited number of existing facilities that are available for modification and because these facilities are located overseas, the residual risks that must be accepted by the NGNP Program include (but are not limited to):

1. Risk associated with negative intrusive actions by the foreign government involved

2. Risk associated with delayed or inadequate communications (e.g., due to translator unavailability and translation errors) between the test facility(ies) and the NGNP Program

3. Risk associated with an inadequate level of control over test facility scheduling and prioritization, particularly in the case of partial or non-funding by DOE

4. Risk associated with an inadequate level of control over test data package quality, particularly in the case of partial or non-funding by DOE.

As discussed previously, this alternative can also be implemented in several different ways using different contracting strategies. Thus, the selected implementation method can result in varying the amount of residual risk, including the introduction of new risks, as well as different considerations for planning and performing systems engineering and technical management:

- In the case where testing services are procured from a "user" facility after necessary modifications are made, the CTC systems engineering and technical management activities would be primarily concerned with the specification and procurement of the testing services as well as verification of test data deliverables. It is assumed that the requirements for the facility modification are directly derived by the facility owner from the test specifications and attributes of the SSCs to be tested. This type of option does not appear to trigger DOE O 413.3A applicability, and the NGNP Program's technical effort relative to mitigating the residual risks should be manageable under the NGNP PEP or NGNP SEMP, if applicable, and the NGNP Risk Management Plan.

- In the case where DOE is a "partner" or "leaser" in an upgraded "user" facility and retains some ownership in the capital investment, it is conceivable that certain funding methods could have the potential to trigger applicability of DOE O 413.3A requirements for the design, procurement, and 
construction aspects of the facility upgrade. However, it is assumed that funding will occur through a grant or other mechanism that does not invoke such applicability. In either case, the NGNP Program will need to mitigate the residual risks noted above as well as perform systems engineering and technical management activities, consistent with a systems engineering approach, to protect DOE's ownership stake in the modified facility. These actions will also help ensure that the facility will be able to provide the requisite testing capability and data quality at completion. As such, DOE G 413.3-1 should be applied as a best management practice, and the tailored systems engineering and technical management controls should be covered in and performed per the NGNP PEP or NGNP SEMP, as applicable.

\subsection{Alternative 4 - Component Test Facility}

In Alternative \#4, a single, standalone facility (the CTF) will be constructed to house and operate test loops designed to meet NGNP material and technology development and large-scale testing needs for the HTGR prototype. The CTF, including any supporting utilities, will be constructed in the United States, where it will be fully-funded, owned, and operated by DOE or its representatives. This alternative triggers applicability of DOE O 413.3A requirements for planning, implementing, and completing the facility using a systems engineering approach. As such, it is advisable to document the planning for and tailoring of systems engineering and technical management processes and activities in a SEMP specific to the CTF Project. Figure 2 illustrates how the SEMP can be implemented within the DOE O 413.3A critical decision $(\mathrm{CD})$ process as well as for anticipated subcontracting provisions.

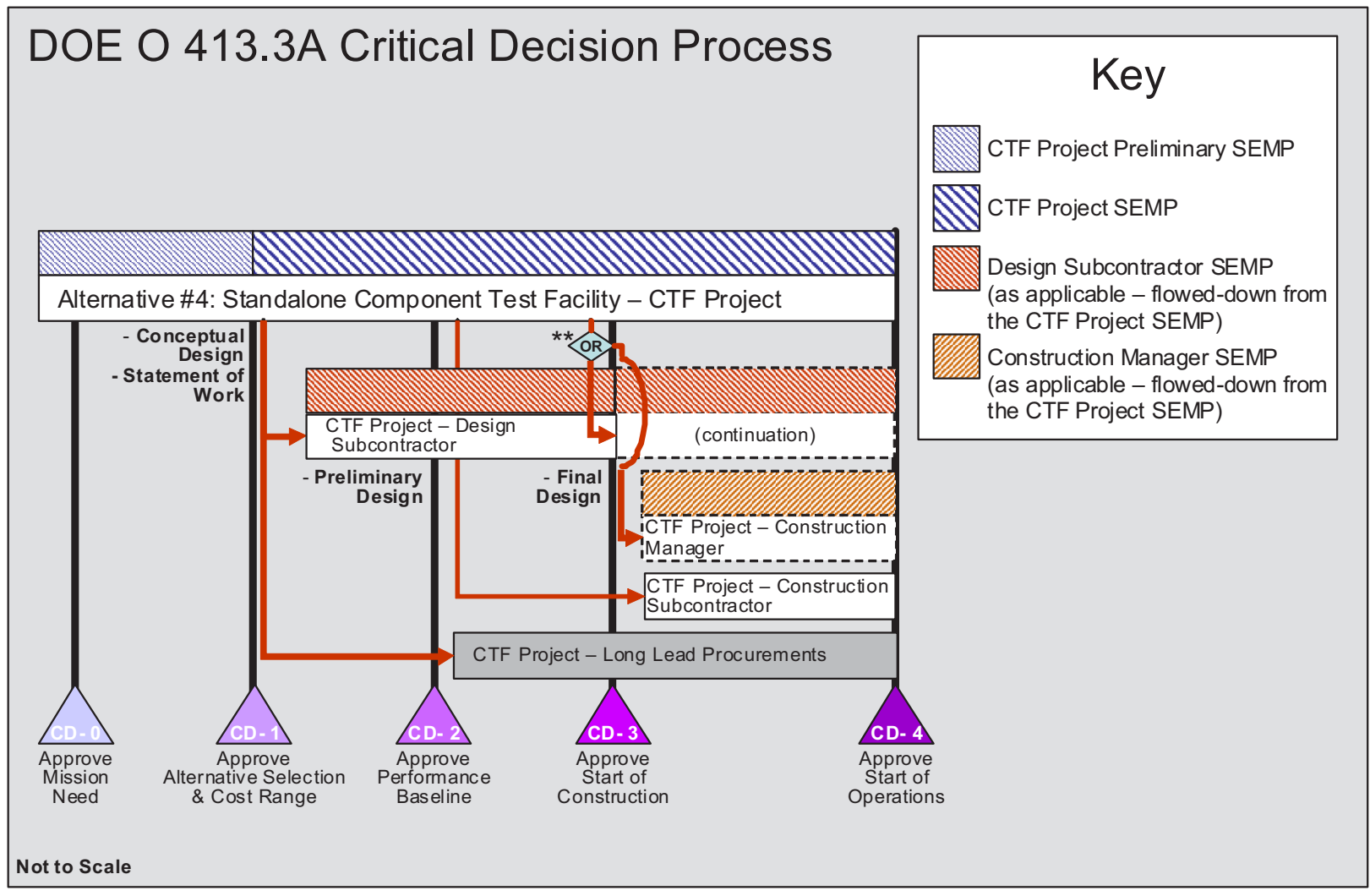

Figure 2. SEMP Applicability for Alternative \#4, Component Test Facility

As shown in Figure 2, a Preliminary SEMP can cover the period from CD-0 to CD-1. This recognizes that the SEMP is a living document and allows for significant changes to occur in the revised CTF SEMP based on decisions that are finalized by CD-1. These decisions primarily relate to those 
reflected in the Conceptual Design and Acquisition Strategy, including the procurement of design and construction management resources. These versions of the SEMP will need to define not only the scope and tailoring of systems engineering and technical management processes to be performed at the CTF Project level, but also the flowdown (e.g., through procurement Statements of Work) of requirements for associated processes, activities, and deliverables to be performed or delivered by any subcontractors involved.

\section{RECOMMENDATIONS}

It is recommended that systems engineering and technical management processes and activities related to the establishment of the CTC be addressed as presented in Figure 1 and as described in Section 3 , according to the selected alternative. 